\title{
Chemical, mechanical, thermal analysis of a nano ceramic embedded novel composite material for automotive and industrial applications
}

\author{
H.K.G.K.D.K. Hapuhinna ${ }^{*}$, R.D. Gunaratne ${ }^{*}$, H.M.J.C. Pitawala ${ }^{* *}$ \\ * Department of Engineering Technology, University of Sri Jayewardenepura, Sri Lanka \\ ${ }^{* * *}$ Department of Science \& Technology, Uva Wellassa University, Sri Lanka \\ DOI: $10.29322 /$ IJSRP.10.08.2020.p104112 \\ http://dx.doi.org/10.29322/IJSRP.10.08.2020.p104112
}

\begin{abstract}
Study describes the processing of nano ceramic/ polyester composite using a polyester matrix with different mixing ratios of nano-hydroxyapatite ceramic as the reinforcement and the filler. Processed products were analyzed to find out; physical, chemical, mechanical, thermal properties including reinforcement particle size distribution, composition, presence of functional groups, crystallography, surface morphology, structural features, thermal stability, a variation of glass transition temperatures and tensile properties. Results have shown high thermal stability, material stability with good mechanical properties in the processed nano-products. The study concluded, after incorporating polyester with nano-ceramic lead to have products with higher properties for automotive and industrial applications.
\end{abstract}

Index Terms- Hydroxyapatite, Solid state sintering, Polymer matrix composites, Automotive applications

\section{INTRODUCTION}

$\mathrm{C}$ omposites consist of two or more constituents that are not soluble in each other, in terms; those constituent materials are combined on a macroscopic scale to form a useful third material. The harder reinforcing phase available in the form of particles, flakes, woven mats, fibers or whiskers etc. imbedded in the matrix phase which may ductile and continuous. ${ }^{[1]}$

Specially, researchers have shown those lightweight composite materials offer a great potential for increasing efficiency of vehicles while requiring less energy, boosting the fuel economy, maintaining safety and reducing the exhaust emission with improved ride performance including reduction of noise, vibration, harshness etc. ${ }^{[14-18]}$

Considering that, we have processed a nano ceramic composite with polyester as the matrix material and a nano ceramic powder which inhouse synthesized material as the reinforcement. Used nano hydroxyapatite ceramic filler was solid state synthesized value-added product of Chloroapatite mineral that has several industrial applications due to its range of properties. ${ }^{[19-28]} 101$ Polyester (PA) was chosen as the light weight, low cost polyester matrix. It is a medium thixotropic, pre-accelerated, unsaturated, orthophthalic polyester resin with high wear resistance which is particularly suitable for molding casting and laminating in the manufacturing industries of boats, water tanks, bathtubs, portable, flower pots, chairs, trays etc. ${ }^{[29]}$

This study is fully aimed to process and analysis novel nano ceramic polyester composite which can be used for industrial applications including automotive structural applications for car bumpers, brakes, clutch plates etc.

\section{MATERIAL AND METHODS}

\section{A. Composite preparation}

Table 1. Masses of ceramic filler and polyester resin mixtures for composite samples

\begin{tabular}{|l|c|c|}
\hline \multirow{2}{*}{ Sample Name } & \multicolumn{2}{|c|}{ Composition (Wt\%) } \\
\cline { 2 - 3 } & $\begin{array}{c}\text { Polyester } \\
\text { mixture }\end{array}$ & $\begin{array}{c}\text { Nano-hydroxyapatite } \\
\text { ceramic }\end{array}$ \\
\hline NP material (control) & 100 & 0 \\
\hline SSHAp 5\% composite & 95 & 5 \\
\hline SSHAp 10\% composite & 90 & 10 \\
\hline SSHAp 15\% composite & 85 & 15 \\
\hline SSHAp 20\% composite & 80 & 20 \\
\hline SSHAp 25\% composite & 75 & 25 \\
\hline SSHAp 30\% composite & 70 & 30 \\
\hline SSHAp 35\% composite & 65 & 35 \\
\hline SSHAp 40\% composite & 60 & 40 \\
\hline SSHAp 45\% composite & 55 & 45 \\
\hline SSHAp 50\% composite & 50 & 50 \\
\hline SSHAp 55\% composite & 45 & 55 \\
\hline SSHAp 60\% composite & 40 & 60 \\
\hline SSHAp 65\% composite & 35 & 65 \\
\hline SSHAp 70\% composite & 30 & 70 \\
\hline SSHAp 75\% composite & 25 & 75 \\
\hline SSHAp 80\% composite & 20 & 80 \\
\hline SSHAp 85\% composite & 15 & 85 \\
\hline SSHAp 90\% composite & 10 & 90 \\
\hline SSHAp 95\% composite & 5 & 95 \\
\hline
\end{tabular}

First solid-state synthesized ceramic was ball milled using a planetary ball mill (TENCAN, XQM-0.4A) over $24 \mathrm{hrs}$ to obtain 
more fine particles. Resulted nano-hydroxyapatite powder was taken as the ceramic filler material. ${ }^{[19,20]}$

Next masses of the filler and polyester resin mixture were mixed according Table 1 below to process the series of nano-ceramic incorporated polyester composite samples.

The masses of the 101PA, unsaturated polyester resin was calculated according to the required volume of cast, the Cobalt naphthalate accelerator and the MEKP, hardener was added as weight $\%$ with an amount of $0.05 \%$ and $1 \%$ respectively.

Using an overhead stirrer, nearly for $150 \mathrm{rpm}$ stirring rate, weighed amounts of polyester resin, hardener, filler and the catalyst were mixed together thoroughly for nearly 30 minutes at the room temperature continuously and slowly to avoid bubbling during mixing. After that, the mixture was uniformly poured from one corner into the molds until the required level of filling (to avoid bubbles formation which may led to cast damage).

Then the mixture was left in the mold for $24 \mathrm{hrs}$ at room temperature to solidify. Finally, after placing them inside a dryer oven for $48 \mathrm{hrs}$ at $(60-75){ }^{\circ} \mathrm{C}$ to reveal complete polymerization, best coherency, and to relieve residual stresses; samples were taken out from the molds to do further analysis.

\section{B. Composite analysis}

Solid state sintered ball milled hydroxyapatite powder was analyzed under Malvern nano- particle analyzer (MAL1184267) to find out its particle size distribution. Then the NP material, crosslinked pure polyester matrix material without reinforcement was taken as "control" and series of ceramic filler added polyester matrix composites were analyzed with Fourier transform infra-red spectroscopy (Bruker - Alpha [FTIR] spectroscopy) over the region $400-4000 \mathrm{~cm}^{-1}$ using $\mathrm{KBr}$ pellet technique with the resolution of $4 \mathrm{~cm}^{-1}$ to obtain composition, mainly the presence of functional groups. Scanning electron microscopy with energy dispersive X-ray spectroscopy (SEM with EDS) (Hitachi SU6600 with AZtec software) was carried out to examine elementary composition, presence of impurities and surface morphology micro/nano structural features of all processed composites. Also, the sample mixtures of all new nano-hydroxyapatite ceramic polyester composites were studied using X-ray diffractometer (Rigaku - Ultima. IV diffractometer) in reflection mode with $\mathrm{CuK} \alpha 1: 0.154 \mathrm{~nm}$ radiation, scanned speed of $1.5^{\circ} \mathrm{min}^{-1}$ within $15^{\circ}-80^{\circ}$ ranged angles as $2 \theta$ values to determine their crystallographic phases. Differential scanning colorimetry was done for the processed composites using DSC PT1000 (DSC_A_7016_17_0) instrument with N environment, $100{ }^{0} \mathrm{C} \mathrm{min}{ }^{-1}$ heating rate up to $650{ }^{\circ} \mathrm{C}$ maximum temperature to find out their variation of glass transition temperatures ( $\mathrm{Tg}$ values). After that, Thermo gravimetric analysis (TGA) was done only for contro, SSHAp 15\% and SSHAp 50\% composite samples using a thermal analyzer (SDT Q600) with $\mathrm{N}$ environment, $20{ }^{\circ} \mathrm{C} \mathrm{min}^{-1}$ heating rate and $1450{ }^{\circ} \mathrm{C}$ maximum temperature to find out the thermal stability of composite with the addition of filler. At last, Tensile test was performed at room temperature using Tensile Strength Tester (Testometric M50050CT) for all composite samples including control to find out best mixing ratio of filler and the polyester matrix having highest tensile properties. For that, ASTM E 8/E 8M - 08 standard sample specimens were used.

\section{RESULTS AND DISCUSSION}

\section{A. Nano particle Analysis}

Particle analysis was performed for hydroxyapatite ceramic filler samples to find out its distribution of size. Results have shown diameter of filler particle, distributed around average value of $419.7 \mathrm{~nm}$ with a standard deviation of $56.85 \mathrm{~nm}$. It has proven that the filler particles in nano meter range which tend to be in spherical shape.

\section{B. EDS Analysis}

Table 2. Comparison of EDS results between NP material, SSHAp 15\% and SSHAp 50\% composites

\begin{tabular}{|c|c|c|c|c|c|c|}
\hline \multirow{2}{*}{ Element \% } & \multicolumn{2}{|c|}{ NP material } & \multicolumn{2}{c|}{$\begin{array}{c}\text { SSHAp 15\% } \\
\text { composite }\end{array}$} & \multicolumn{2}{c|}{$\begin{array}{c}\text { SSHAp 50\% } \\
\text { composite }\end{array}$} \\
\cline { 2 - 7 } & Avg & SD & Avg & SD & Avg & SD \\
\hline C & 76.9 & 0.91 & 65.4 & 0.31 & 66.7 & 0.42 \\
\hline O & 22.8 & 1.01 & 33.7 & 0.65 & 32.4 & 0.73 \\
\hline Ca & - & - & 0.6 & 0.25 & 0.6 & 0.22 \\
\hline P & - & - & 0.2 & 0.13 & 0.2 & 0.12 \\
\hline Si & 0.3 & 0.12 & 0.1 & 0 & 0.1 & 0 \\
\hline
\end{tabular}

Avg - Average value SD - Standard Deviation

As indicated in Table 2 it can be clearly stated that NP material is only comprised of normal polyester resin, hardener and accelerator consists of $\mathrm{C}, \mathrm{O}$ and Si elements. Comparing it's result with SSHAp $15 \%$ and SSHAp $50 \%$ polyester composites results show that; after the addition of nano-hydroxyapatite as the ceramic filler, $\mathrm{Ca}$ and $\mathrm{P}$ elements have added to the polyester composites. Also, Avg and the SD values describe that the repetition of values is more consistent.

\section{FTIR analysis}

According to the Figure 1; all ceramic added polyester composites consists of $560 \mathrm{~cm}^{-1}, 640 \mathrm{~cm}^{-1}, 963 \mathrm{~cm}^{-1}, 1028 \mathrm{~cm}^{-}$ ${ }^{1}, 1110 \mathrm{~cm}^{-1}$ and $3572 \mathrm{~cm}^{-1}$ peaks related to the hydroxyapatite ceramic. That may occur with the addition of ceramic filler. Further the $560 \mathrm{~cm}^{-1}, 640 \mathrm{~cm}^{-1}, 963 \mathrm{~cm}^{-1}, 1110 \mathrm{~cm}^{-1}$ and $1028 \mathrm{~cm}^{-}$ ${ }^{1}$ peaks related with the presence of $\mathrm{PO}_{4}{ }^{-3}$ groups and the 3572 $\mathrm{cm}^{-1}$ peak exhibits the characteristic $\mathrm{OH}^{-}$peak in the hydroxyapatite.

Also, some peaks nearly $1117 \mathrm{~cm}^{-1}, 1286 \mathrm{~cm}^{-1}, 1726 \mathrm{~cm}^{-1}$ and $2986 \mathrm{~cm}^{-1}$ can be found within NP material as well as in all ceramic filler added polyester composites. Those peaks directly related to the polyester group of the mixture. Normally, $1117 \mathrm{~cm}^{-}$ $1,1286 \mathrm{~cm}^{-1}, 1726 \mathrm{~cm}^{-1}$ and $2986 \mathrm{~cm}^{-1}$ related with the $\mathrm{C}-\mathrm{O}, \mathrm{C}=\mathrm{O}$ and C-H (alkyl) stretches accordingly. ${ }^{[19,20]}$ 


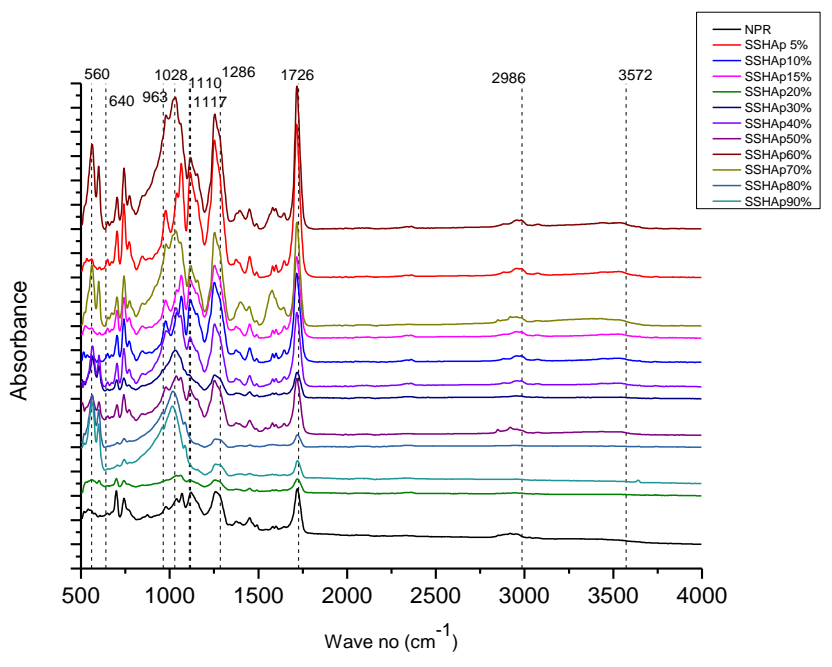

Figure 1. Resulted FTIR curves for processed composites

\section{XRD analysis}

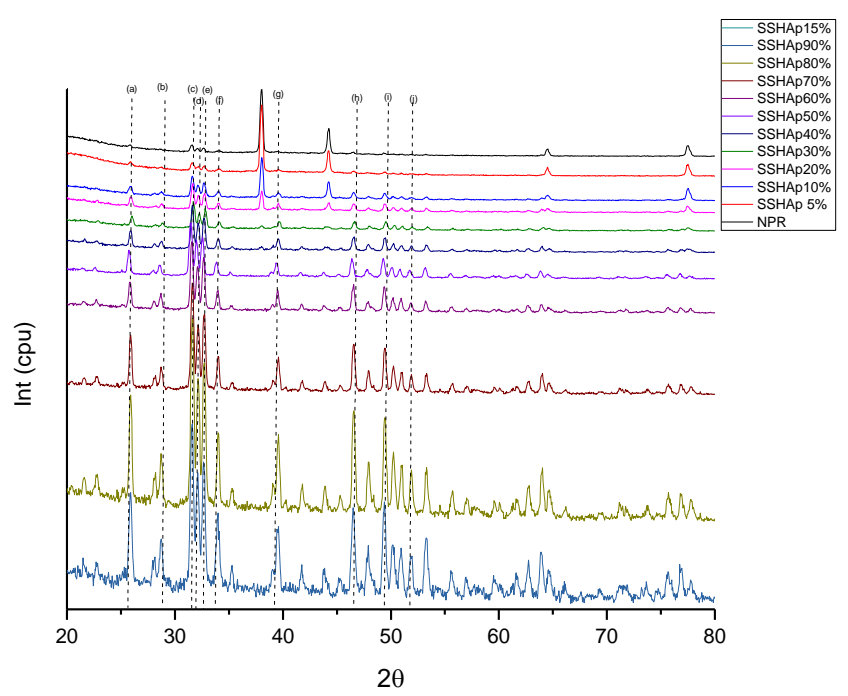

Figure 2. Resulted XRD patterns for processed composites

As mentioned in the Figure 2, when consider (a) - (j) peaks which are mentioned in the resulted XRD patterns for processed ceramic polyester composites apart from NP material related to the $002,210,211,112,300,202,310,222,213$ and 004 crystallographic phases of hexagonal hydroxyapatite ceramic filler in order. Both peaks which occurred in the processed ceramic polyester composites as well as the NP material may occur due to the polyester. Also considering the XRD pattern it can be concluded that the processed composites contain crystalline properties. ${ }^{[19,20]}$

\section{E. DSC analysis and Tensile test}

Table 3 \& Figure 3 have shown; with the addition of ceramic up to $15 \%$, processed composites' $\mathrm{Tg}$ values have increased due to the increasement of crosslinked density or with the increasement of number of cross links between polyester molecules and internal heat transfer. ${ }^{[30]}$ As that, tensile strength /mechanical and thermal properties of the composites are increased parallelly. With the excess addition of ceramic than $15 \% \mathrm{Tg}$ value has decreased that may sue to the free volume occupied, agglomerations and the sample degradation etc. The highest average value for tensile strength can be found within SSHAp $15 \%$ composite samples. Therefore, it can be concluded 15\% ceramic filler added polyester composites is the best mixing ratio.

Table 3. DSC and Tensile analyzed results for all processed composites

\begin{tabular}{|c|c|c|c|}
\hline \multirow{2}{*}{ Sample Name } & \multirow{2}{*}{$\begin{array}{c}\text { Glass } \\
\text { transition } \\
\text { temperature } \\
\mathrm{Tg}\left({ }^{\circ} \mathrm{C}\right)\end{array}$} & \multicolumn{2}{c|}{$\begin{array}{c}\text { Maximum Tensile } \\
\text { Strength } \sigma_{\text {Max }}(\mathrm{MPa})\end{array}$} \\
\cline { 3 - 4 } & Avg value & $\begin{array}{c}\text { SD } \\
\text { value }\end{array}$ \\
\hline NP material (control) & 72.5 & 14.3 & 0.08 \\
\hline SSHAp 5\% composite & 74.9 & 14.1 & 0.79 \\
\hline SSHAp 10\% composite & 75.8 & 13.5 & 0.83 \\
\hline SSHAp 15\% composite & 77.9 & 18.7 & 1.25 \\
\hline SSHAp 20\% composite & 76.7 & 15.6 & 1.84 \\
\hline SSHAp 30\% composite & 74.8 & 12.7 & 1.15 \\
\hline SSHAp 40\% composite & 70.0 & 10.4 & 0.76 \\
\hline SSHAp 50\% composite & 71.9 & 5.9 & 1.17 \\
\hline SSHAp 60\% composite & 71.7 & 9.2 & 1.23 \\
\hline SSHAp 70\% composite & 68.9 & 3.8 & 0.98 \\
\hline
\end{tabular}

Avg -Average value SD-Standard Deviation *** $80 \%, 85 \%, 90 \%$ and $95 \%$ ceramic filler added polyester composites are too much brittle. Therefore, there DSC and Tensile results have not included in the table.

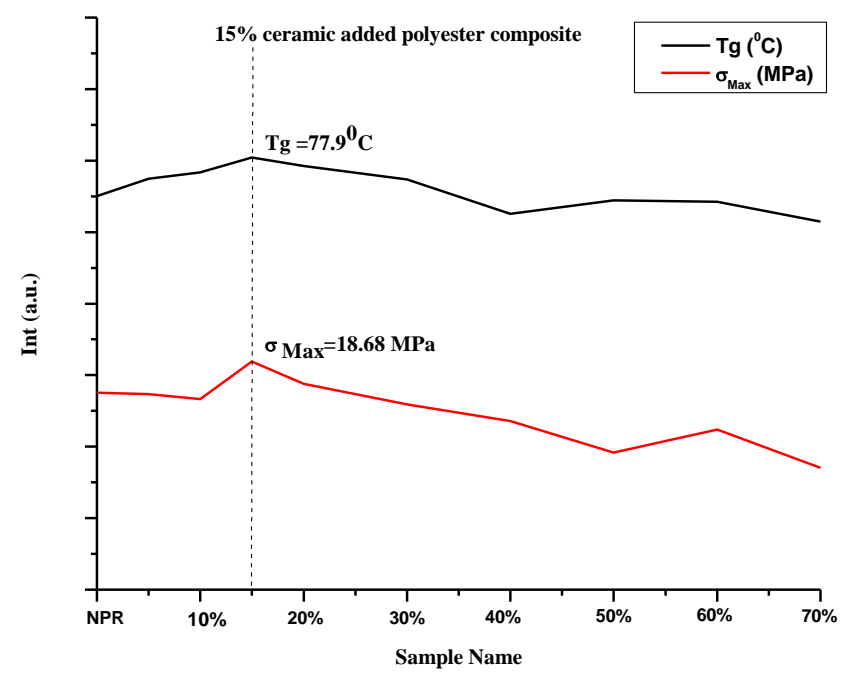

Figure 3. Comparison of $\mathrm{Tg}$ and $\sigma_{\mathrm{Max}}$ values of processed composites 


\section{F. TGA analysis}

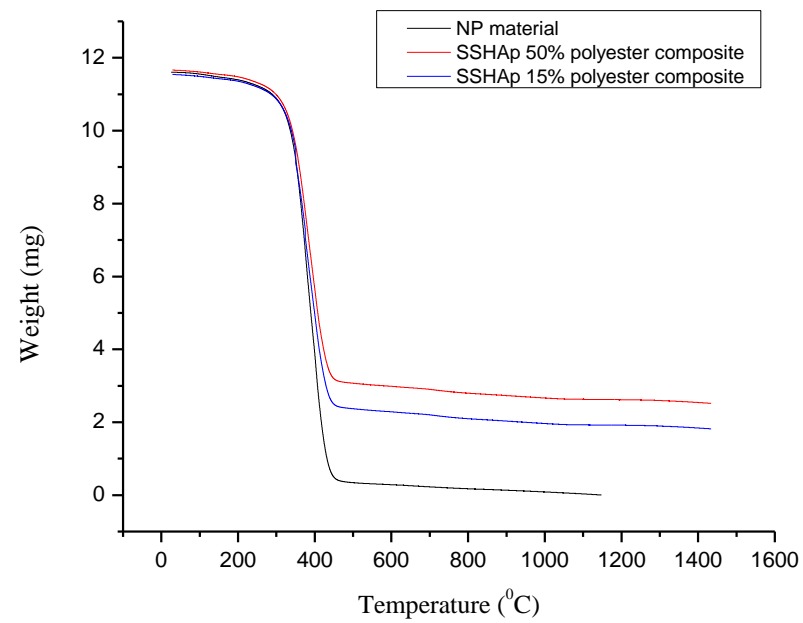

Figure 4. Comparison of TGA results between NP material, SSHAp $15 \%$ and SSHAp 50\% composites

Similar pattern of weight loss can be found within all three curves in the Figure 4. With the addition of hydroxyapatite ceramic filler, composites overall weight loss has decreased than the control, which may occur due to higher heat absorbance of hydroxyapatite ceramic than the polyester. Therefore, it can be concluded that amount of weight loss of control has reduced after incorporating nano hydroxyapatite ceramic as the reinforcement as well as the filler and the ceramic filler added polyester composites perform good thermal stability and good material stability in nature and applications than the pure crosslinked polyester material without reinforcement.

\section{G. SEM analysis}

Considering Figure 5-8 SEM images of all processed composites; 100k images have shown that all composites have unique continuous surface in the $500 \mathrm{~nm}$ range. Those images contain boundaries or cracks that may occur due to the gold coating of samples while analyzing samples under the SEM. When examine the 5k images; they have clearly exhibited that free volume has reduced with the addition of nano ceramic filler within SSHAp $15 \%$ and SSHAp 50\% samples and with the excess addition of nano ceramic filler, sample lead to have some porous structure which improve the brittleness of structure as shown in SSHAp $90 \%$. Those results coincided with the Tensile \& DSC results as well.

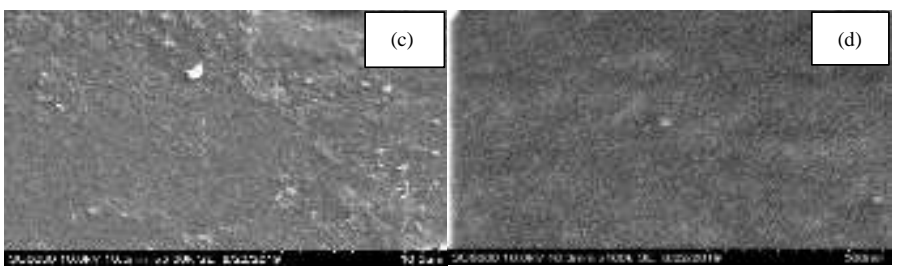

Figure 5. SEM images of NP material; 10kv, (c)5k (d)100k

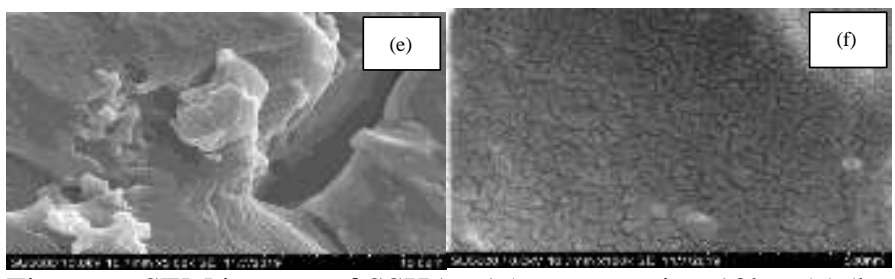

Figure 6. SEM images of SSHAp $15 \%$ composite; 10kv, (e)5k (f) $100 \mathrm{k}$

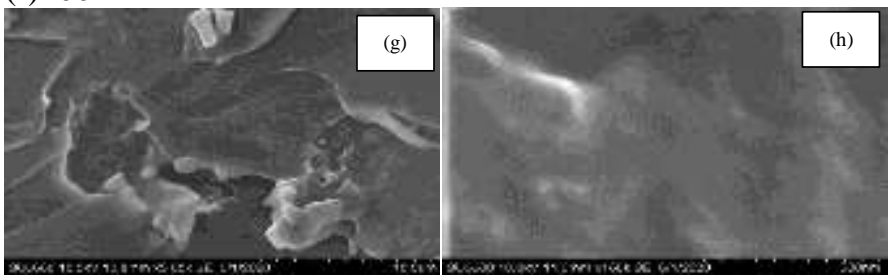

Figure 7. SEM images of SSHAp 50\% composite; 10kv, (g)5k (h) $100 \mathrm{k}$

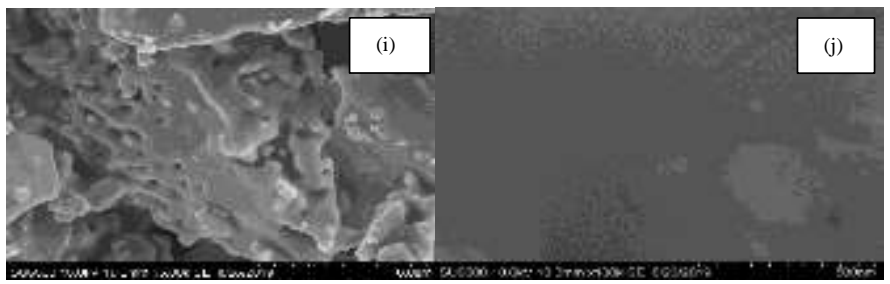

Figure 8. SEM images of SSHAp 90\% composite; 10kv, (i)5k (j) $100 \mathrm{k}$

\section{CONCLUSION}

Finally, the study concludes that processed nano-hydroxyapatite ceramic filler added polyester composites can be used for automotive applications such as car bumpers, brake pads/liners, internal and external structural parts etc. Also, it can be used for other industrial applications such as for structural parts in building constructions, bridge repairing, for sports ware - cricket baseball etc. ${ }^{[31,32]}$ considering its better tensile properties good material stability and thermal stability in nature than the pure polyester crosslinked material without reinforcement.

Hydroxyapatite ceramic has a higher melting point nearly 1670 ${ }^{0} \mathrm{C}$ and with that it's ability of absorbing more heat energy lead to process nano-hydroxyapatite incorporated polyester composites with better thermal and material properties than the pure polyester resin. Amongst them SSHAp 15\% composite has shown highest $\mathrm{Tg}$ value and higher tensile properties. At, 15\% Hydroxyapatite nano-composite has increased its crosslink density due to high thermal absorption of nano ceramic with high heat conductivity and higher surface area due to nano particle size; beyond that maximum tensile peek has passed and oxidative degradation starts during fully cured composites.

Resulted nano hydroxyapatite ceramic added polyester composites consisted of unique continuous composite surface and excess addition of ceramic, above $75 \%$ increases brittleness. That may occur due to the decrease of free volume, decrease of polyester and ceramic bonding capacity with the addition of ceramic as mentioned in the SEM images. Therefore, excess 
addition of ceramic, above $75 \%$ more porous, brittle structure can be found within processed ceramic polyester composites.

\section{ACKNOWLEDGEMENT}

This research was fully funded by the University Research Grants, University of Sri Jayewardenepura, Sri Lanka, Grant no: ASP/01/RE/TEC/2017/43.

\section{REFERENCES}

[1] zohdy (2018). Applications of ceramics. [online] Slideshare.net. Available at: https://www.slideshare.net/ZOTTY/applications-of-ceramics [Accessed 3 Feb. 2018].

[2] Mechstuff4u.com. (2018). Advantages and disadvantages of ceramics. [online] Available at: http://www.mechstuff4u.com/2017/03/advantages-anddisadvantages-of-ceramics.html [Accessed 3 Feb. 2018]. [3] Theseus.fi. (2018). AUTOMOBILE BRAKE SYSTEM. [online] Available at: https://www.theseus.fi/bitstream/handle/10024/111425/Shi\%20Shenshen\%20The sis\%20AUTOMOBILE\%20BRAKE\%20SYSTEM.pdf?sequence $=1$ [Accessed 2 Feb. 2018].

[4] Mogaji, P., Jamiru, T., Desai, D. and Sadiku, R. (2018). A Critical Survey of Ceramics Materials for Production of Automotive Engine Block. [5] Anon, (2018). Different Methods to Synthesize Ceramic Foams. [online] Available

https://www.researchgate.net/publication/248455868_Different_Methods_to_Syn thesize_Ceramic_Foams [Accessed 7 Feb. [6] Anon, (2018). Review on Ceramic Application in Automotive Turbocharged Engines. [online] Available at:https://www.researchgate.net/publication/272944637_Review_on_Ceramic_A pplication_in_Automotive_Turbocharged_Engines [Accessed 7 Feb. 2018]. [7] Baldus, P. (2018). Ceramic Fibers for Matrix Composites in HighTemperature Engine Applications. [8] Quinn, G. and Morrell, R. (2018). Design Data for Engineering Ceramics: A Review of the Flexure Test. [9] Patil, K., Aruna, S. and Mimani, T. (2018). Combustion synthesis: an update. [10] Lange, H., Wötting, G. and Winter, G. (2018). Silicon Nitride-From Powder Synthesis to Ceramic Materials. [11] Naskar, A., Keum, J. and Boeman, R. (2018). Polymer matrix nanocomposites for automotive structural components. [12] LACKEY, W., STINTON, D., CERNY, G., SCHAFFHAUSER, A. and FEHRENBACHER, L. (2018). Ceramic Coatings for Advanced Heat Engines-A Review and Projection. [13] Pujari, V., Tracey, D., Foley, M., Paille, N., Pelletier, P., Sales, L., Willkens, C. and Yeckley, R. (2018). Reliable ceramics for advanced heat engines. [online] Osti.gov. Available at: https://www.osti.gov/biblio/64606-reliable-ceramics$\begin{array}{lllll}\text { advanced-heat-engines } & \text { [Accessed } & 11 & \text { Feb. } & 2018 \text { ]. }\end{array}$ [14] Becher, P. (2018). Microstructural Design of Toughened Ceramics. [15] Larson, N. and Zok, F. (2018). In-situ 3D visualization of composite microstructure during polymer-to-ceramic conversion. [16] Coppola, A., Faruque, O., Truskin, J., Board, D., Jones, M., Tao, J., Chen, Y. and Mehta, M. (2018). Validation of Material Models For Automotive Carbon Fiber Composite Structures Via Physical And Crash Testing (VMM Composites Project).

[17] Riegel, J. (2018). Exhaust gas sensors for automotive emission control. [18] Vaidyaraman, S., Purdy, M., Walker, T. and Horst, S. (2018). C/SiC Material Evaluation for Aircraft Brake Applications. [19] Hapuhinna, H., Gunaratne, R., Pitawala, H., Wijesekara, K. and Ekanayake, E. (2017). Synthesis and characterization of hydroxyapatite from Eppawala Rock Phosphate for Biomedical Applications as a value added product. [online]. Available from: Tradmed International (International Symposium on Traditional and complementary Medicine. [20] Hapuhinna, H. ; Gunaratne, R. ; Pitawala, H. (2018), 'Development of a
Biomaterial from Naturally Occurring Chloroapatite Mineral for Biomedical Applications', World Academy of Science, Engineering and Technology, International Science Index 140, International Journal of Chemical, Molecular, Nuclear, Materials and Metallurgical Engineering, 12(8), $380-388$. [21] H.K.G.K.D.K. Hapuhinna, R.D. Gunaratne, H.M.J.C. Pitawala (2019); A novel approach of synthesizing 2-hydroxyethyl methacrylate embedded hydroxyapatite composites for dentistry applications ; Journal of Engineering Research and Application www.ijera.com ISSN : 2248-9622 Vol. 9,Issue 4 (Series -1) April 2019, pp 51-57, DOI: http://dx.doi.org/10.9790/9622$0904015157 /$

[22] H.K.G.K.D.K. Hapuhinna, R.D. Gunaratne, H.M.J.C. Pitawala (2019); Synthesis of bone cement from a natural mineral for biomedical industry; International Journal of Scientific and Research Publications (IJSRP) 9(4) (ISSN: 2250-3153), DOI: http://dx.doi.org/10.29322/IJSRP.9.04.2019.p8872 [23] Hapuhinna, K., Gunaratne, R. and Pitawala, J. (2019) Comparison between Differently Synthesized Hydroxyapatite Composites for Orthopedic Applications. Journal of Materials Science and Chemical Engineering, 7, 16-28 https://doi.org/10.4236/msce.2019.75002

[24] Kalinga Hapuhinna, Rajitha Deshapriya Gunaratne \& Jagath Pitawala (2019): A ceramic composite derived from high-grade rock phosphate as a substitution for human bone, Materials Technology, DOI 10.1080/10667857.2019.1623531

[25] H.K.G.K.D.K. Hapuhinna, R.D. Gunaratne, H.M.J.C. Pitawala (2019); Comparison between differently synthesized hydroxyapatite composites for dentistry applications; International Journal of Scientific and Research $\begin{array}{llll}\text { Publications } & \text { (IJSRP) } & \text { 9(7) } & \text { (ISSN: }\end{array}$ DOI:http://dx.doi.org/10.29322/IJSRP.9.07.2019.p9137

[26] Hapuhinna K, Gunaratne R, Pitawala J (2019) Comparison between differently synthesized hydroxyapatite composites for orthopedic applications. Journal of Materials Science and Chemical Engineering 7(5): 16-28. [27] HKGKDK Hapuhinna, RD Gunaratne, HMJC Pitawala. Synthesis of Hydroxyapatite 2-Hydroxyethyl Methacrylate Blended Material for Dentistry. Adv Complement Alt Med. 4(5). ACAM.000599.2019. DOI 10.31031/ACAM.2019.04.000600.

[28] Hapuhinna, H. ; Gunaratne, R. ; Pitawala, H. (2019), 'A Composite Developed from a Methyl Methacrylate and Embedded Eppawala Hydroxyapatite for Orthopedics', World Academy of Science, Engineering and Technology, International Science Index 140, International Journal of Chemical, Molecular, Nuclear, Materials and Metallurgical Engineering, 13(6), $270 \quad$ - 279 [29] IJERAIffcochemicals.com. (2019). Unsaturated Polyester Resins | IFFCO Chemicals. [online] Available at: http://iffcochemicals.com/products/unsaturatedpolyester-resins/ [Accessed 17 Oct. [30] Young, R. and Lovell, P. (2011). Introduction to Polymers. Boca Ratón, FL: CRC

Press.

[31] Strumberger, N., Gospocic, A., Hvu, M. and Bartulic, C. (2005). Polymeric Materials in Automobiles. Promet - Traffic - Traffico (PROMET-ZAGREB), 17(3), $\quad$ pp.149 - 160 [32] Ravishankar, B., Nayak, S. and Kader, M. (2019). Hybrid composites for automotive applications - A review. Journal of Reinforced Plastics and Composites, 38(18), pp.835-845.

\section{AUTHORS}

First Author - H.K.G.K.D.K. Hapuhinna is with Department of Engineering Technology, University of Sri Jayewardenepura, Sri Lanka, khapuhinna@ymail.com

Second Author - R.D. Gunaratne is with Department of Engineering Technology, University of Sri Jayewardenepura, Sri Lanka, rajitha@sjp.ac.lk

Third Author - H.M.J.C. Pitawala is with Department of Science \& Technology, Uva Wellassa University, Sri Lanka Correspondence Author - R.D. Gunaratne (Rajitha Deshapriya Gunaratne), rajitha@sjp.ac.lk,+94705758877 